\title{
The role of interviewer encounters in panel responses on life satisfaction
}

\author{
Adrian Chadi* \\ The Institute for Labour Law and Industrial Relations in the European Union (IAAEU), University of Trier, 54286 Trier, Germany
}

\section{H I G H L I G H T S}

- The study sheds light on the panel effect of declining life satisfaction responses.

- Unfamiliarity with an interviewer can affect people's response behavior.

- Interviewer changes trigger increases in reported life satisfaction.

- The negative trend is mostly determined by the overall time spent in the panel.

- The findings help to answer the question of how to deal with such response artifacts.

\begin{abstract}
A B S T R A C T
This note examines a common explanation why participants of panel surveys may report declining life satisfaction over time. In line with the argument of developing trust relationships between interviewers and interviewees, the analysis reveals positive effects in reported life satisfaction when the person conducting the interview changes to an unfamiliar individual. Yet, the evidence also shows that the overall decline is determined by years in the panel, rather than by number of encounters with one specific interviewer.
\end{abstract}

\section{Introduction}

Panel data is the preferred type of data for empirical researchers of life satisfaction. Among other things, it allows researchers to consider personality-related baseline levels of happiness for each individual which, due to the seminal work by Ferrer-i-Carbonell and Frijters (2004), has become a standard requirement in research on the determinants of subjective well-being. While longitudinal data permits analyses that are impossible to perform with crosssectional data, it also reveals potential flaws in the information coming from survey participants. One phenomenon that receives increased attention is the so-called "panel effect" in life satisfaction responses (see e.g. D'Ambrosio and Frick (2012), Frijters and Beatton (2012), Kassenboehmer and Haisken-DeNew (2012), Wunder

\footnotetext{
* Tel.: +496512014774.

E-mail address: chadi@iaaeu.de.
}

et al. (2013)). Also known by the term "panel conditioning" it is simply defined as an effect resulting from answering the same question several times. For life satisfaction, the common finding is a negative trend in the data (e.g. Van Landeghem (2012)). Yet, due to a lack of research on the actual causes of this phenomenon, researchers often give rather ad hoc explanations, and they do not apply a uniform solution to this problem. ${ }^{1}$

One explanation for the panel effect of declining life satisfaction responses is the so-called "learning effect" (see e.g. Frick et al.

\footnotetext{
1 The standard approach is to expand empirical models with a linear counter variable, which increases by one with every year of participation (see e.g. Frijters et al. (2004): Headey et al. (2010)). Kassenboehmer and Haisken-DeNew (2012) additionally include years in panel squared. Wunder et al. (2013) exclude all information from first and second interviews of each person. As a mixed approach, D'Ambrosio and Frick (2012) drop all first interviews and include dummies for number of interviews in their dynamic analysis of well-being and income.
} 
(2006), Wooden and Li (forthcoming)). ${ }^{2}$ Another argument often given by researchers relates to people's desire to not report honestly on their unhappiness when there is a lack of trust. In this vein, Frijters and Beatton (2012) point to increased honesty as driving force behind the negative time-in-panel trend, which they consider an important factor in revealing the true relationship between well-being and age. Like Baetschmann (forthcoming), they conclude that previous findings in the literature may be biased when such response artifacts are ignored. Kassenboehmer and HaiskenDeNew (2012) also point out the significance of considering years in the panel and argue that, over time, there is a growing trust relationship between interviewee and interviewer.

The motivation for this note builds specifically upon this argument. On closer inspection, the idea of developing trust in an interviewer requires interviewees to be confronted with the same person each year. However, for many panel participants, this assumption may not be true. While survey organizers typically aim to reduce respondent attrition by fostering personal relationships between interviewees and interviewers, they cannot prevent attrition of the latter, for instance, when interviewers decide to quit their job. In such cases, interviewees necessarily experience an exogenous change of person conducting the interview. Besides, participants may not be confronted with a person at all, if a visit-free interview mode is allowed by survey organizers. Having such variation allows for a deeper analysis of the trust-in-interviewer argument by comparing the effects of being visited by a specific interviewer with the potential effects of overall time in the panel. In addition to this, a specific phenomenon can be expected to emerge in the data if interviewer encounters play a significant role in people's response behavior. If survey participants report more positively about their lives when being visited by an interviewer for the first time, the trust-in-interviewer hypothesis would suggest that, in cases of interviewer changes, satisfaction responses go up again. As all previous studies have only considered overall panel participation time, the present study is the first to test whether this is true and how significant such an effect may be.

Following a brief description of the panel data used, some graphical illustrations prior to the multiple regression analyses help to clarify the main points of this investigation. The final section discusses results and draws conclusions for future empirical research.

\section{Empirical application}

This note exploits data from the German Socio-Economic Panel Study (SOEP), a large representative survey of households in Germany (see Wagner et al. (2007)). ${ }^{3}$ The availability of identification numbers in the SOEP allows interviewer identification in all interview modes with interviewer presence. ${ }^{4}$ To determine the number of times an interviewee encounters a specific interviewer, identifiers must be available for all interviews during an interviewee's panel career, which leads to a different sample than in previous

\footnotetext{
2 This idea implies that data quality generally increases over time, as participants make use of the life satisfaction scale in a way that they do not in the first few times. Resulting from a learning process, participant answers become more accurate year by year while, initially, they report too high levels of life satisfaction.

3 Life satisfaction is obtained in the SOEP on a scale ranging from 0 to 10 , with higher scores indicating greater well-being. The wording is: "How satisfied are you with your life, all things considered?"

4 These modes are oral and partly oral interviews (either with paper and pencil or with computer assistance) as well as self-completed questionnaires with an interviewer present. In roughly one third of all cases, participants fill out questionnaires without an interviewer present. This happens when a household member is not at home during the visit or when there is contact via mail only. Note that there are also a few atypical modes, such as telephone interviews. These are dropped from the analysis, just like interviews in the presence of interpreters.
}

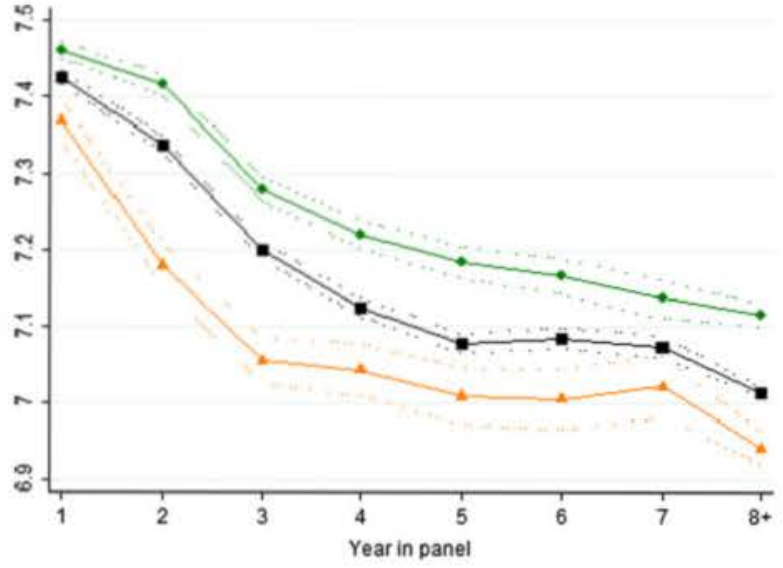

Fig. 1. Average life satisfaction and years in panel. Figure shows unweighted life satisfaction averages of all participants (black squares), of those who only respond to the same interviewer who conducted the first interview (green circles) and of those who only fill out questionnaires without interviewer presence (yellow triangles) by year of participation.

Note: The dotted lines always label $95 \%$ confidence intervals.

Source: SOEP data from 1985 to 2011.

studies using SOEP data. ${ }^{5}$ Nevertheless, the application of the same methodological approach as in Frijters and Beatton (2012) as well as in Kassenboehmer and Haisken-DeNew (2012) allows the comparison of results regarding the panel effect. Accordingly, the analyses here also make use of pooled ordinary least squares (OLS) and OLS with fixed individual effects.

Fig. 1 shows the standard pattern of declining life satisfaction responses by year in panel. To examine the intervieweeinterviewer relationship more closely, the decline is also shown for those who only respond to the same interviewer who conducted the first interview. Yet, apart from an almost constant difference in life satisfaction levels, the picture is similar when examining the quasi control group of interviewees who solely fill out questionnaires on their own, i.e. without interviewers. This comparison suggests that it is overall participation in the panel that determines the decline in reported well-being. To examine what happens when an interviewee meets a different interviewer than before, Fig. 2 shows life satisfaction averages for those participants in the sample who are visited at least four times in a row by one interviewer but prior to that four times in a row by a different person. The finding of a remarkable shift in the trend of declining life satisfaction substantiates the above expectation.

Multiple regression analyses verify whether the findings remain significant when potentially relevant factors are considered as controls. In particular, there is a good reason for interviewer changes, which is when SOEP participants move to a different location. Thus, the standard control variables commonly used in previous studies are expanded with variables for recent moves. Also included are many variables capturing potential differences in standard of living.

The first step is to reproduce the standard finding in the literature. Table 1 does that by showing a linear years-in-panel effect, yet, with one important objection. As soon as year effects are considered, the negative effect disappears in fixed-effects models. The explanation for this is closely related to the discussion of why linear age cannot be used in such models (see Ferrer-i-Carbonell and Frijters (2004)). Only the fact that some interviewees refuse to participate every year allows use of a linear variable for years in panel

5 Note that there are no interviewer identification numbers available for the first SOEP wave of 1984. 
Table 1

Life satisfaction and years of participation in panel.

Source: SOEP data from 1985 to 2011 (always 171,052 observations from 22,510 individuals).

\begin{tabular}{|c|c|c|c|c|c|c|}
\hline (a) & \multicolumn{6}{|c|}{ Pooled OLS regressions } \\
\hline $\begin{array}{l}\text { Years in panel } \\
\text { Years in panel squared }\end{array}$ & $-0.025^{\cdots+}(0.001)$ & $-0.025^{\cdots \cdots}(0.001)$ & $-0.025^{\cdots}(0.001)$ & $\begin{array}{l}-0.053^{\cdots *}(0.002) \\
0.001^{\cdots \cdots}(0.000)\end{array}$ & $\begin{array}{l}-0.045^{\cdots *}(0.002) \\
0.001{ }^{\cdots}(0.000)\end{array}$ & $\begin{array}{l}-0.045^{\cdots}(0.003) \\
0.001^{\cdots}(0.000)\end{array}$ \\
\hline Adj. $R^{2}$ & 0.005 & 0.130 & 0.132 & 0.006 & 0.130 & 0.133 \\
\hline Control variables & No & Yes & Yes & No & Yes & Yes \\
\hline Year effects & No & No & Yes & No & No & Yes \\
\hline (b) & \multicolumn{6}{|c|}{ Individual fixed effects OLS } \\
\hline Years in panel & $-0.040^{* *}(0.001)$ & $-0.036^{\cdots *}(0.003)$ & $0.020(0.027)$ & $-0.069^{\cdots *}(0.003)$ & $-0.063^{\cdots *}(0.003)$ & $-0.017(0.027)$ \\
\hline Years in panel squared & & & & $0.001^{\cdots *}(0.000)$ & $0.001^{\cdots *}(0.000)$ & $0.001^{\cdots}(0.000)$ \\
\hline Adj. $R^{2}$ & 0.016 & 0.045 & 0.051 & 0.018 & 0.046 & 0.052 \\
\hline Control variables & No & Yes & Yes & No & Yes & Yes \\
\hline Year effects & No & No & Yes & No & No & Yes \\
\hline
\end{tabular}

Robust standard errors are in parentheses.

denotes significance at $1 \%$ level.

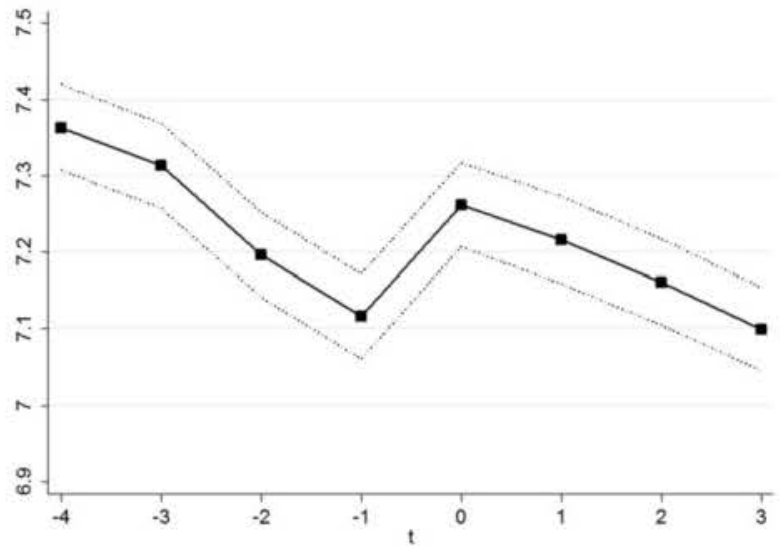

Fig. 2. Average life satisfaction over time and different interviewers (change in $t=0$ ). Figure shows unweighted averages of life satisfaction reported by participants in their fourth last, third last, second last and last interview with an interviewer $(t=-4$ to $t=-1)$ and life satisfaction averages from the first four interviews with a different interviewer $(t=0$ to $t=3)$ who replaced the former one.

Note: The dotted lines always label $95 \%$ confidence intervals.

Source: SOEP data from 1985 to 2011.

together with wave dummies, whereas perfect collinearity would result when those persons with breaks in their panel careers are excluded. This suggests using dummies to capture the panel effect in life satisfaction responses if both fixed individual and year effects are considered simultaneously.

The outcomes presented in Table 2 demonstrate whether interviewer changes trigger increases in reported well-being when a variety of potential influencing factors are controlled for. ${ }^{6}$ The key dummy variable here reflects all initial interviews with different interviewers who replaced the first one. The significantly positive effect substantiates the above expectation that unfamiliarity with an interviewer can affect people's response behavior. As shown in the table's last column, this finding is robust to inclusion of full sets of year-in-panel and interview mode dummy variables.

The next part of the analysis checks whether there is a particular trend in reported life satisfaction that is related to increasing familiarity with the interviewer. Due to the above findings, a full set of interviewer encounter dummy variables is used together with

\footnotetext{
6 The discussion from here on is limited to fixed-effects models as those are standard in the research on well-being. Also note that the complete results of all tables are available from the author upon request.
}

Table 2

Life satisfaction and interviewer changes (OLS with individual fixed effects). Source: SOEP data from 1985 to 2011 (always 171,052 observations from 22,510 individuals)

\begin{tabular}{lllll} 
individuals). & & & & \\
\hline 1st encounters with other & $0.095^{\cdots \cdots}$ & $0.098^{\cdots \cdots}$ & $0.108^{\cdots \cdots}$ & $0.051^{\cdots}$ \\
interviewers than the first & $(0.017)$ & $(0.016)$ & $(0.016)$ & $(0.016)$ \\
Adj. $R^{2}$ & 0.023 & 0.051 & 0.052 & 0.057 \\
\hline Year effects & Yes & Yes & Yes & Yes \\
Control variables & No & Yes & Yes & Yes \\
Year in panel dummies & No & No & Yes & Yes \\
Interview mode controls & No & No & No & Yes \\
\hline Robust standard errors are in parentheses. & & &
\end{tabular}

Robust standard errors are in parentheses.

denotes significance at $1 \%$ level.

dummies to control for the overall participation effect. Results presented in Table 3 confirm the insights from the graphical analysis. While there is a decline in reported well-being linked to interviewee-interviewer encounters that is still robust when including control variables (first column), this trend disappears as soon as the overall participation time is considered (second column). For the sake of clarity, the basic difference in life satisfaction responses between interviews with and without interviewer presence is also controlled for. Consequently, the reference category changes from "no interviewer presence" to "first interview with the first interviewer". The insignificant outcomes indicate that there is no original response trend related to actual interviewee-interviewer encounters, suggesting that the panel effect of declining life satisfaction is dominated by overall time spent in the panel.

However, the importance of the interviewee-interviewer aspect appears again in cases of interviewer changes. The final two columns of Table 3 show significantly positive effects on life satisfaction responses when panel participants are confronted with a second interviewer, and even more so in case of a third interviewer, while smaller effects are found for encounters with interviewers beyond that. ${ }^{7}$ A plausible explanation is that truly unhappy people give less accurate answers to questions from unfamiliar interviewers. The results are robust to a significantly negative "comeback effect" when interviewees are revisited by an earlier interviewer, possibly indicating a special trust effect when reencountering a familiar face. As an additional robustness check, the same analysis is conducted on the basis of a more homogeneous data sample with only interviewees who participated more than eight times and without any break, leading to very similar outcomes. ${ }^{8}$

\footnotetext{
${ }^{7}$ Note that only a few hundred participants in the sample are visited by more than three different interviewers.

${ }^{8}$ See the discussion paper version of this note (Chadi, 2013b) for more information on the interview modes and on the control variables as well as for the complete results of this robustness check.
} 
Table 3

Life satisfaction and interviewer encounters (OLS with individual fixed effects). Source: SOEP data from 1985 to 2011 (always 171,052 observations from 22,510 individuals)

\begin{tabular}{|c|c|c|c|c|}
\hline \multicolumn{5}{|l|}{ First interviewer } \\
\hline 1st encounter & $\begin{array}{l}0.343^{*-} \\
(0.018)\end{array}$ & $\begin{array}{l}0.251^{\cdots} \\
(0.021)\end{array}$ & \multicolumn{2}{|c|}{ Reference category } \\
\hline 2nd encounter & $\begin{array}{l}0.287^{\circ} \\
(0.019)\end{array}$ & $\begin{array}{l}0.249^{-3} \\
(0.021)\end{array}$ & $\begin{array}{l}-0.011 \\
(0.022)\end{array}$ & $\begin{array}{l}0.006 \\
(0.023)\end{array}$ \\
\hline 3rd encounter & $\begin{array}{l}0.252 \\
(0.020)\end{array}$ & $\begin{array}{l}0.253^{\ldots} \\
(0.022)\end{array}$ & $\begin{array}{l}-0.013 \\
(0.024)\end{array}$ & $\begin{array}{l}-0.003 \\
(0.024)\end{array}$ \\
\hline 4th encounter & $\begin{array}{l}0.244^{*} \\
(0.021)\end{array}$ & $\begin{array}{l}0.284^{\ldots .} \\
(0.023)\end{array}$ & $\begin{array}{l}0.016 \\
(0.026)\end{array}$ & $\begin{array}{l}0.024 \\
(0.026)\end{array}$ \\
\hline 5th encounter & $\begin{array}{l}0.258 \\
(0.022)\end{array}$ & $\begin{array}{l}0.304 \\
(0.024)\end{array}$ & $\begin{array}{l}0.037 \\
(0.028)\end{array}$ & $\begin{array}{l}0.044 \\
(0.028)\end{array}$ \\
\hline 6 th encounter & $\begin{array}{l}0.198^{\circ} \\
(0.023)\end{array}$ & $\begin{array}{l}0.262^{\cdots} \\
(0.025)\end{array}$ & $\begin{array}{l}-0.005 \\
(0.029)\end{array}$ & $\begin{array}{l}0.002 \\
(0.029)\end{array}$ \\
\hline 7 th encounter & $\begin{array}{l}0.181^{1 .} \\
(0.025)\end{array}$ & $\begin{array}{l}0.228^{* .} \\
(0.027)\end{array}$ & $\begin{array}{l}-0.036 \\
(0.030)\end{array}$ & $\begin{array}{l}-0.031 \\
(0.030)\end{array}$ \\
\hline 8 th encounter or more & $\begin{array}{l}0.178^{-.} \\
(0.024)\end{array}$ & $\begin{array}{l}0.210 \\
(0.025)\end{array}$ & $\begin{array}{l}-0.055^{\circ} \\
(0.029)\end{array}$ & $\begin{array}{c}-0.050^{\circ} \\
(0.029)\end{array}$ \\
\hline \multicolumn{5}{|l|}{ Second interviewer } \\
\hline 1st encounter & $\begin{array}{l}0.312^{* *} \\
(0.022)\end{array}$ & $\begin{array}{l}0.323^{* *} \\
(0.022)\end{array}$ & $\begin{array}{l}0.060^{\circ} \\
(0.026)\end{array}$ & $\begin{array}{l}0.062 " \\
(0.026)\end{array}$ \\
\hline 2nd encounter & $\begin{array}{l}0.280^{\circ} \\
(0.026)\end{array}$ & $\begin{array}{l}0.308 \\
(0.026)\end{array}$ & $\begin{array}{l}0.041 \\
(0.030)\end{array}$ & $\begin{array}{l}0.049 \\
(0.030)\end{array}$ \\
\hline 3rd encounter & $\begin{array}{l}0.302 \\
(0.028)\end{array}$ & $\begin{array}{l}0.3411^{\prime *} \\
(0.029)\end{array}$ & $\begin{array}{l}0.070^{-} \\
(0.033)\end{array}$ & $\begin{array}{l}0.075^{*} \\
(0.033)\end{array}$ \\
\hline $\begin{array}{l}4 \text { th encounter } \\
\text { or more }\end{array}$ & $\begin{array}{l}0.270^{\circ} \\
(0.029)\end{array}$ & $\begin{array}{l}0.305^{\ldots} \\
(0.029)\end{array}$ & $\begin{array}{l}0.034 \\
(0.034)\end{array}$ & $\begin{array}{l}0.037 \\
(0.034)\end{array}$ \\
\hline \multicolumn{5}{|l|}{ Third interviewer } \\
\hline 1st encounter & $\begin{array}{l}0.4011^{\cdots} \\
(0.041)\end{array}$ & $\begin{array}{l}0.428^{\cdots *} \\
(0.041)\end{array}$ & $\begin{array}{l}0.163^{\cdots} \\
(0.044)\end{array}$ & $\begin{array}{l}0.162 \cdots \\
(0.044)\end{array}$ \\
\hline 2nd encounter & $\begin{array}{l}0.395 \\
(0.048)\end{array}$ & $\begin{array}{l}0.421^{\cdots} \\
(0.048)\end{array}$ & $\begin{array}{l}0.154 \\
(0.051)\end{array}$ & $\begin{array}{l}0.161 \\
(0.051)\end{array}$ \\
\hline 3rd encounter & $\begin{array}{l}0.460 \\
(0.058)\end{array}$ & $\begin{array}{l}0.486 \\
(0.058)\end{array}$ & $\begin{array}{l}0.215^{*} \\
(0.060)\end{array}$ & $\begin{array}{l}0.219 \\
(0.060)\end{array}$ \\
\hline 4 th encounter or more & $\begin{array}{l}0.373^{\cdots} \\
(0.058)\end{array}$ & $\begin{array}{l}0.388^{\cdots} \\
(0.058)\end{array}$ & $\begin{array}{l}0.115^{\circ} \\
(0.061)\end{array}$ & $\begin{array}{l}0.117^{\circ} \\
(0.061)\end{array}$ \\
\hline $\begin{array}{l}\text { Encounters with } \\
\text { further interviewers } \\
\text { Reencounter with a } \\
\text { previous interviewer }\end{array}$ & $\begin{array}{l}0.366^{\circ} \\
(0.059)\end{array}$ & $\begin{array}{l}0.365 \\
(0.059)\end{array}$ & $\begin{array}{l}0.101^{\prime} \\
(0.060)\end{array}$ & $\begin{array}{l}0.100^{\circ} \\
(0.060) \\
-0.094^{\cdots} \\
(0.024)\end{array}$ \\
\hline Adj. $R^{2}$ & 0.055 & 0.056 & 0.058 & 0.058 \\
\hline Year effects & Yes & Yes & Yes & Yes \\
\hline Control variables & Yes & Yes & Yes & Yes \\
\hline Year in panel dummies & No & Yes & Yes & Yes \\
\hline Interview mode controls & No & No & Yes & Yes \\
\hline $\begin{array}{l}\text { Robust standard errors are } \\
\text { specifications is all intervie } \\
\text {.. denotes significance at } \\
\text {... denotes significance at } \\
\text { denotes significance at }\end{array}$ & $\begin{array}{l}\text { vel. } \\
\text { el. } \\
\text { el. }\end{array}$ & Referen & $\begin{array}{l}\text { ategory } \\
\text { ce. }\end{array}$ & he first $t$ \\
\hline
\end{tabular}

\section{Discussion}

This note shows how interviewer changes in a panel can lead to more positive life satisfaction responses, indicating that the level of familiarity with the interviewer affects respondent behavior. As interviewer attrition is an unavoidable aspect of panel surveys, this is an important and intriguing finding. Contrary to expectations proposed in the literature, however, the evidence suggests that the decline in reported well-being is mostly determined by the overall time spent in the panel, not necessarily by developing trust relationships between interviewees and interviewers. Whether this points to a learning effect or to a trust-in-the-institution effect is up to further research to establish.

Researchers have identified the age-happiness discussion as an important case, in which panel effects require particular atten- tion. ${ }^{9}$ While there are other satisfaction determinants which one can think of, such as tenure, in which a variable of interest increases over time, there are also research objectives for which interviewer changes may pose a serious threat to the validity of empirical outcomes if not considered in the investigation. One example is the analysis of mobility and its impact on life satisfaction. Imagine a researcher ignores interviewer changes and finds a significant but biased increase in reported life satisfaction in the year of a move. The consideration of the familiarity-with-the-interviewer factor appears necessary to convince an informed reader of the results' validity.

In order to capture response bias effects from interviewer changes, dummy variables can be used. Dealing with the overall panel effect is not that straightforward. Whereas for the first few years the decline in life satisfaction responses appears as almost linear, researchers need to be aware of the potential correlations between year-in-panel variables and variables for age and year effects. Thus, based on the above findings, the advice is to also consider using dummy variables in order to distinguish between new and more experienced panel participants, in particular, if fixedeffects estimators are applied.

A more general implication from this study relates to the significant role of the interview mode, which needs to be taken into account when empirically analyzing life satisfaction, and also in further research on the role of survey methodology. While the very large positivity bias for interviewer presence seems remarkable, it has been found that even the presence of third persons during the interview can trigger increases in reported life satisfaction (Chadi, 2013a). These findings from studying SOEP data are quite similar to those for British panel data by Conti and Pudney (2011). Whereas they emphasize people's desire to report more positively when being confronted with visitors, Wooden and Li (forthcoming) find only little evidence for panel effects when studying Australian data, suggesting a need of further research on how different survey characteristics affect life satisfaction responses. In this vein, the final, but probably most important, suggestion is to always check a data set's underlying survey design in order to make the most suitable decisions concerning potential response artifacts.

\section{Acknowledgments}

I am grateful to Peter Krause and Simone Bartsch for helpful advice. For comments and discussions, I thank Daniel Arnold, Laszlo Goerke, Clemens Hetschko, Sabrina Jeworrek, Tobias Pfaff, an anonymous referee, and the participants of the IAAEU seminar.

\section{References}

Baetschmann, $\mathrm{G}_{i,}$ 2013. Heterogeneity in the relationship between happiness and age: evidence from the German socio-economic panel. German Economic Review (forthcoming).

Chadi, A., 2012. I would really love to participate in your survey! Bias problems in the measurement of well-being. Economics Bulletin 32, 3111-3119.

Chadi, A., 2013a. Third person effects in interview responses on life satisfaction. Journal of Applied Social Science Studies 133, 323-333.

Chadi, A., 2013b. The role of interviewer encounters in panel responses on life satisfaction. IAAEU Discussion Paper 11/2013, Trier.

Conti, G., Pudney, S., 2011. Survey design and the analysis of satisfaction. Review of Economics and Statistics 93, 1087-1093.

D'Ambrosio, C., Frick, J.R., 2012. Individual wellbeing in a dynamic perspective. Economica 79, 284-302.

\footnotetext{
9 Additional regressions with linear age and age squared variables for a working age sample suggest that the analysis of the so-called " $u$-shape effect" is not only affected by the panel effect but also by the way that it is considered. Since an investigation into the age effect would require a more comprehensive discussion, e.g. with respect to potential collinearity problems, the results are not examined further here. Moreover, the analysis of the effect of becoming older may also be biased by additional response artifacts (see Chadi (2012)).
} 
Ferrer-i-Carbonell, A., Frijters, P., 2004. How important is methodology for the estimates of the determinants of happiness? Economic Journal 114, 641-659.

Frick, J.R., Goebel, J., Schechtman, E., Wagner, G.G., Yitzhaki, S., 2006. Usin Analysis of Gini (ANOGI) for detecting whether two subsamples represent the same universe: the German Socio-Economic Panel Study (SOEP) experience. Sociological Methods and Research 34, 427-468.

Frijters, P., Beatton, T., 2012. The mystery of the U-shaped relationship between happiness and age. Journal of Economic Behavior and Organization 82, 525-542.

Frijters, P., Haisken-DeNew. J.P., Shields, M.A., 2004. Investigating the patterns and determinants of life satisfaction in Germany following reunification. Journal of Human Resources 39, 649-674.

Headey, B., Muffels, R., Wagner, G.G., 2010. Long-running German panel survey shows that personal and economic choices, not just genes, matter for happiness. Proceedings of the National Academy of Sciences 107, 17922-17926.
Kassenboehmer, S.C., Haisken-DeNew, J.P., 2012. Heresy or enlightenment? The well-being age U-shape effect is flat. Economics Letters 117, 235-238.

Van Landeghem, B., 2012. Panel conditioning and self-reported satisfaction: evidence from International panel data and repeated cross-sections. In: SOEPpapers 484. DIW, Berlin.

Wagner, G.G., Frick, J.R., Schupp. J., 2007. The German Socio-Economic Panel Study (SOEP)-scope, evolution and enhancements. Journal of Applied Social Science Studies 127, 139-170.

Wooden, M., Li, N., 2013. Panel conditioning and subjective well-being. Social Indicators Research (forthcoming).

Wunder, C., Wiencierz, A., Schwarze, J., Küchenhoff, H., 2013. Well-being over the life span: semiparametric evidence from British and German longitudinal data. Review of Economics and Statistics 95, 154-167. 